\title{
Women in Leadership: Insights from Female Principals of Rural Secondary Schools in Vhembe District of South Africa
}

\author{
Livhalani Bridget Sinyosi ${ }^{1}$ and Onoriode Collins Potokri* \\ ${ }^{1}$ Department of Education Leadership and Management, College of Education, Muckleneuk Campus, \\ University of South Africa, Gauteng 0181, South Africa \\ ${ }^{2}$ Faculty of Education, University of Johannesburg, Gauteng 2006, South Africa
}

\begin{abstract}
Gender predisposition towards female leaders within the South African context remains a problem and compelling issue, particularly in rural settings, which are often marginalised and overlooked. Guided by the transformational leadership theory, this article explored the experiences of South African female principals in managing secondary schools in the Vhembe District of Limpopo. A profoundly traditional and patriarchal society characterises this rural setting. Hence, a qualitative research approach and a case study design were used. Ten female principals from ten (10) randomly selected secondary schools in the Vhembe District were purposively selected to serve as participants. Through semi-structured interviews, data were gathered from the sampled participants. Findings from the article reveal that patriarchy still plays a role in disadvantaging women from effectively assuming their duties as leaders. Most of the participants-female principals are subjected to gender bias and thus, unproductive, impact the cooperation from learners, parents, teachers, the community, and the Department of Education officials. Despite unpleasant experiences, female leaders in this article demonstrate selflessness in their daily leadership tasks and routines. Furthermore, they are inspirational and serve as role models to all they had relationships with for the transformation and change they desire in their schools. To the sampled principals, being selfless and inspirational is their leadership strength. One way of the few mentioned becoming a leader one aspires to.
\end{abstract}

ARTICLE INFO

Received: 21 January 2021

Accepted: 26 April 2021

Published: 15 September 2021

DOI: https://doi.org/10.47836/pjssh.29.3.10

E-mail addresses:

sinyosiliba@gmail.com (Livhalani Bridget Sinyosi)

cpotokri@uj.ac.za, cnuvie@gmail.com (Onoriode Collins Potokri)

* Corresponding author
Keywords: Gender equality, school management, transformation theory, women leadership

\section{INTRODUCTION}

Researchers often cite gender bias against female leaders as a leadership bottleneck, especially in Western world schools. 
However, in South Africa, the issue is more of a pandemic (Schmidt \& Mestry, 2015). Moraka (2018) posits that, although the Constitution addresses gender equality, women in the education sector still do not experience equal rights in practice. Hence, the predominance of males in educational leadership posts continues to define the South African culture (Zuma, 2018). In South Africa, women dominate the teaching profession (Mestry \& Schmidt, 2012). Nevertheless, there remains a dearth of women in leadership positions. For example, in Vhembe district of the Limpopo Province-the context of the study from which this article is drawn-13.5\% of all secondary school principals in the district, according to recent 2018 statistics from Vhembe District Data. On a national level, female teachers make up about $68 \%$ of the South African teaching force. However, only $36 \%$ of principals are women (Davids, 2018). These statistics attest to the current national problem of women under-representation in school leadership positions.

According to Gibbons et al. (2017), despite the post-Apartheid government's gender equality measures, such as assigning more women in senior managerial and leadership positions, activists remain hesitant regarding their impact. Exacerbated by historical and cultural stereotypes, together with the failures of the system to enforce prescripts regarding gender parity and affirmative action, most South African women have been confined mainly to middle or lower positions in the education sector (Johnson \& Mathur-Helm, 2011). Thus, this resulted in a significant gap between the number of men and women occupying the position of the secondary school principal. In the light of this, this article explored female school principals' experiences to understand how they manage their schools.

\section{PROBLEM STATEMENT}

Despite the prevailing problem of gender inequalities in South Africa, little research has been conducted regarding the phenomenon. Of the few studies conducted, most (e.g., Botes, 2014; Mestry \& Schmidt, 2012; Zikhali \& Smit, 2019) have been conducted on the urban environment and overlooking the rural schools. Botes (2014, p. 1) argues that "while rural-based women are often silent, hidden and under-appreciated, they represent probably the world's most powerful untapped natural resource, and they are surely more than ever before a key to world stability and understanding".

There are two dominant narratives in research about female principals and educational leadership. The first centres on women's struggles in accessing leadership positions-internal and external. The second relates to what women must deal with in retaining those positions (Davids, 2018). The latter narrative underpins the specific objective of this article. In particular, it links to women's experiences in the management of secondary schools in South Africa using the Vhembe District as a case study. Thus, this article contributes to the empirical literature by highlighting and exploring the lived experiences of female principals in rural secondary schools. 
WHAT DOES LITERATURE TELL US?

\section{Gender Discrimination in South African Education System}

The South African Department of Education (Diko, 2014) maintains that gender discrimination against women is still prevalent, as observed in the relatively fewer women in fundamental managerial positions within the education sector, despite the more significant proportion of women being educators. Younger and Cobbett (2014) argue that there are active measures to mitigate against this discrimination. However, it will take a longer period to fulfil these objectives. Diko (2014) further reveals that research focusing on gender bias against women within the education system of South Africa shows the growing practice of barring women from being endorsed to managerial positions, especially in secondary schools. For Batton and Wright (2019), this status quo needs to be challenged because women are proficient leaders as their male counterparts. Cubillo and Brown (2003) also confirm that the experiences of women who desire and attain managerial posts are controversial and worthy of further inquiry so that a more precise picture can be portrayed.

Diko (2014) espoused, the South African Department of Basic Education states that women have been exposed to adverse stereotyping for many years. Furthermore, women are often still anticipated to be passive and more dependent on their male counterparts. They are indeed not projected to be ambitious and assertive in their quest for appointment in leadership positions. Diko argues further that this tenacity of women's negative stereotyping is partly due to most men and women's roles in society. For example, women are still regarded as homemakers, whereas most males are employed outside the home (Posel \& Bruce-Brand, 2020; Potokri, 2015). Such stereotyping is confirmed by the lack of women in top management positions in the South African education system.

Moorosi (2008) points out that cultural stereotypes attribute school principalship with masculinity, hampers women's promotion to higher posts within the education sector. One typical consequence of the negative stereotyping of women is that they are often not credited with having the adequate innate ability to be successful. Instead, their success is attributed to external factors such as excellent teaching. The Department of Basic Education (Zuma, 2018, p. 28) maintains that "schools must aim at shifting these attitudes by instituting gender awareness programs that transcend barriers both in curricular and extra-curricular activities". Aside using gender awareness programmes, females leaders and their colleagues who aspire to become leaders must learn and lean towards transformational patterns and styles that use interpersonal skills to actively instigate a discussion with those already in leadership to reach a consensus decision and avoiding confrontation through encouragement and compromise that develop them into adopting of a participative approach (see Flanders, 1994; Rigg \& Sparrow 1994). 


\section{Experiences of Female Principals in South African Secondary Schools}

Despite the South African government's strategies, mechanisms, and policies to curb gender inequality in state institutions, Diko (2014) reveals that secondary schools generally favour males taking up leadership roles. Females tend to be more popular as principals in elementary schools in South Africa rather than secondary schools because females relate better to younger children (Department of Education, 2008). Zuma (2018) points out that apartheid policies compound the challenges women face in educational management in South Africa, even in this era when democratic policies should protect and support the advancement of women leaders. According to Makgoka (2016), the general belief that leadership in the education sector is aligned to males meant that female principals in South African secondary schools receive backlash from their male counterparts and female teachers, learners, and parents.

In research conducted on females who managed to get into managerial positions within Gauteng's secondary school, Zikhali and Smit (2019) uncovered that some of those promoted became irritated and ultimately resigned from their leadership posts due to social, individual, and workrelated barriers. Accordingly, factors that account for their irritation and resignation include backbiting, jealousy, rejection of authority by pupils, parents, and colleagues, lack of support from colleagues, lack of role models, and discrimination. In addition, Makgoka (2016) highlights that secondary school female principals experience administrative challenges including the grievances of parents, limited resources, time management, and staff handling. On the other hand, there are personal challenges such as wavering self-confidence, balancing work and social lives, and home conflicts.

Relating his study to secondary schools, Arar and Abramovitz (2013, p. 10) emphasises that "women find it difficult undertaking school principalship in rural, remote schools because parents and the community members still view this role through the stereotype of an authoritarian married male". To collaborate Arar's view, Makgoka (2016, p. 62) argues that "patriarchal culture remains dominant in many rural communities and schools in South Africa, playing formidable constraints on women's advancement to principalship". Thus, this has created an atmosphere whereby women often find it challenging to be accepted as equals by their male counterparts. It suggests a failure to implement transformation within the education system. Consequently implies that females are overlooked as per their constitutional bestowed right of equality which could positively impact their appointment to, or retention in, educational leadership positions (Diko, 2014).

Yulianti et al.'s (2020) work, titled 'School efforts to promote parental involvement: The contributions of school leaders and teachers, which was conducted in Indonesia, provides practical thought on how school leaders can be successful in the involvement of parents in their children 
school activities and as well contribute to the general good of the school. Accordingly, they hypothesised that transformational school leadership for parental involvement and inviting behaviour of teachers encourage parents to become more intensely involved with their child's education. However, contrary to their hypothesis, findings from their study through multilevel regression analyses showed that transformational leadership did not directly affect parental involvement. Thus, significant effects were found of teacher invitations on parental involvement. In particular, teacher invitations contributed to school-based parental involvement, such as recruiting parents as volunteers and involvement in decision-making at school. Accordingly, school leaders and teachers are two essential agents within the school organisation to promote parental involvement invariably enhancing the parent's relationship with the school leader and teachers.

\section{The Policy Context of Gender Inequality in the South African Education System}

In terms of gender, the South African Parliament is one of the most progressive globally (Brothers, 2020). A woman heads the country's Department of Basic Education. In addition, the Department of Women, Youth and Persons with Disabilities and several ministries are occupied by women, but challenges still prevail. One noticeable challenge rather than the problem is some departments' inconsiderate attitudes towards gender sensitivity in leadership positions. For the focus of this article, it must be noted that not all the education departments across the country's nine provinces are vehemently pursuing gender equality policies in education because, at the moment, some do not have concrete gender policies in place. This situation has undesirable effects on schools. For instance, students do not have positive role models, and the school management tends not to prioritise gender issues in filling leadership positions. Based on this, South African researchers and practitioners, as prescribed by Diko (2014, p. 828), need to tackle the following question: "What factors might be impeding the implementation of the progressive policy of gender equality in educational leadership and management in schools?"

The government has initiated specific attempts to reverse gendered thinking around management and leadership in education. One of these is the South African Schools Act of 1996 (SASA), accountable for forming School Governing Bodies (SGBs). This act, among its many objectives, attempts to remedy the gendering of responsibilities in schools. It abolishes gender stereotyping of management and the apartheid's top-down approach to education leadership. It also permits the various school interest groups, including women, the right to be embodied in school governance and leadership and to lead (Department of Education, 1996). Despite this corrective step, according to Mestry and Du Plessis (2020), SASA does not do enough as it fails to specify measures to avoiding reformation of the conventional gendered power relations in 
school leadership and governance. Instead, it promotes the perpetuation of past practices, particularly in rural areas where this article focused on, as well as in townships where parents are not literate enough to participate in such management effectively.

School principals, predominantly male, continue to lead schools through their implementation and interpretation of SASA (Diko, 2014). Subsequently, gendered practices prevail continuously in some schools. Zuma (2018), cognisant of this tendency to revert to the familiar, described that females aspiring to become education leaders are still side-lined. Naledi Pandor, a former Minister of Education, disturbed about this continuing situation, in 2004 said that where women strive for managerial roles, there is a notable failure to open space for them (Diko, 2014).

\section{THEORETICAL FRAMEWORK}

From the literature, it is clear that several factors influence women's institutional leadership and management roles. To address these factors, a transformation that policies and the constitution of the Republic of South Africa seek must be indeed legitimised across sectors, especially the education sector. For this reason, transformational leadership theory was used as the article's framework.

Leithwood et al. (1994, p. 230) state that transformational leadership is viewed as leadership that "implies major changes in the form, nature, function and/or potential of some phenomenon applied to leadership". Denmark (2012) states that this leadership theory is more appropriate for educational management than others. Transformational leadership theory best aligns with this article because it focuses on building good relationships with subordinates, the ability to advise subordinates, care about subordinates, advise subordinates regarding career development, building a good relationship with all stakeholders, and being interested in their affairs. Cognisant of this, the article assumes that if female principals adopt transformational leadership theory in the Vhembe District, the whole community will admire their leadership style. Thus, it will go a long way in mitigating gender bias against female principals in schools.

Marks and Printy (2003) argue that transformational leadership theory applies well when the underlining barriers affecting women to rise in leadership positions are addressed. Chabalala (2006) argues that women have as much potential as men and should be given equal rights to exercise their capabilities to remedy their injustices. English (2008) further points that if women are given the right platform to express themselves, they can be productive and effective leaders. According to Burns (1978), transformational leadership involves establishing oneself as a role model by gaining the trust and confidence of followers; the leader ensures that followers are consciously aware of the importance of sharing organisational goals and values.

Furthermore, Burns states that transformational leaders motivate their followers to go beyond their interests and work for the organisation by appealing to the higher-level needs of followers. 
With transformational leadership, the process of influencing significant changes in attitudes and assumptions of organisational members and building commitment for the organisational mission and objectives is possible (Yuk1, 1989, 2005). Therefore, the relationship between a transformational leader and followers is characterised by pride and respect (Bass \& Avolio, 1990). In such circumstances, "the level of trust and confidence in the leader is usually high because subordinates are proud to identify themselves with the leader and thus, develop a strong sense of loyalty" (Silva \& Mendis, 2017, p. 20).

\section{MATERIALS AND METHOD}

A qualitative research methodology brought to the forefront the varied experiences of women principals. Individual interviews were the main data-gathering tools to explore the uniquely contextualised nature of women principals' experiences. Ten (10) female principals from ten (10) randomly selected secondary schools in the Vhembe District were purposively selected to serve as sampled participants. The Vhembe District comprises twenty-seven circuits, with each circuit comprising primary schools and secondary schools. The researchers selected five circuits from the twenty-seven with the highest number of secondary schools managed by females. Two schools were selected from each of the circuits. The respective principals of the selected schools were requested to participate in the study. Relying on the writings of Creswell (2014), the data were analysed using thematic content analysis of open coding to identify themes. Accordingly, thematic content analysis of open coding is a systematic process for data analysis in which statements are analysed and categorised into themes representing the phenomenon of interest.

Empirical information was broken down into themes, clustered, and coded to find the essence of the information. Ultimately the collated information allowed salient themes to emerge, providing the significant findings of the study. The researchers adhered to strict ethical requirements. Therefore, consent was obtained from all participants. Permission was duly sought and approved from the Limpopo Provincial Department of Education, Vhembe District Department of Education, and the Ethics Committee of the University, where this article emanates the large study. Participants were ensured of their anonymity and were made aware that they could withdraw from the research at any time. No personal information of participants is used in this article to ensure confidentiality. Alphabets such as $\mathrm{P} 1 / \mathrm{SCH}$ 1 were used in place of their names or identities. P1 represents participant 1 , and SCH 1 represents school 1.

To address the issue of replication, the researchers adhered to the tenets of trustworthiness. In the light of this, dependability, transferability, conformability, and credibility of the research data used were sought and ensured.

First, the researchers made sure that the data collected were credible. Therefore, data were collected from relevant people who are informed about the phenomenon under investigation. It had to be female principals 
in rural schools in the Vhembe District of South Africa. The study is delimited because the study was about women leadership insights from female principals of rural schools. Despite collecting data from these people (participants), the researchers ensured that the data collection was not hurriedly done but prolonged to allow participants to provide in-depth information needed for the study. To further ensure credibility, researchers used member checks, as Silverman (2010) and Creswell (2014) advise.

Accordingly, a member check is also known as informant feedback or respondent validation. Member checking was conducted during the interview process and after the study. The researchers engaged the participants in member checking during the interview process by creating a natural rapport to obtain honest and open responses. During the interviews, the researchers restated and summarised information and the questions, then probed the participants further to determine the accuracy of their responses in comparison with their initial responses. Furthermore, at the end of the data collection process, we (the researchers) returned to the participants with the transcribed comments to verify the accuracy of the interpretations.

Secondly, is the aspect of conformability refers to the extent to which the interpretation of the research study may be traced back to the source and that they do not represent someone's ideas but those of the participants (Babbie \& Mouton, 2010). The researchers ensured that the information that was tape-recorded was transcribed without any alterations. Third, the researchers were concerned about dependability. It refers to the accuracy of the data presented and whether people may depend on the information for future use (Gibbs, 2007). We pooled our research expertise and asked for help from other colleagues in the field of women leaders in education to review the codes to determine whether or not they would have coded the data the the same way as we did.

In addition, we went back to the participants after analysing the data to ensure that what was written as an accurate representation of what they meant. To be finally assertive in replicating the study, we ensured that the study is transferable to an acceptable extent. In Babbie and Mouton's (2010) view, transferability refers to the possibility of the type or kind of study being repeated by other people and yielding similar results to those obtained by the previous researcher(s). To achieve this, the researchers documented in detail, as shown in this, article the blueprint used for the study including the research design, research approach, the instruments, and the analysis used. As a result, we believe we will assist researcher(s) to carry out similar studies in the future.

\section{RESULTS AND DISCUSSION}

The findings indicate that female principals in the rural area of the Vhembe district had various experiences as principals. Most of these experiences were shared or common and ranging from positive to negative depending on individual principles. 
These experiences are expressly discussed under the following emerged sub-themes: relationship experiences with learners, teachers, and parents and relationship experiences with other stakeholders, and the DoE support. These are presented below and supported with verbatim quotations from the participants.

\section{Relationship Experiences with the Learners}

Regarding the relationship with learners, the majority of the female principals were concerned about the learners' unseriousness and bad behaviour, which displayed their negative attitude towards the female principals. It is aptly captured by the quotation from P4 /SCH 4, who voiced her experience with her learners as undesirable, as indicated in her words below:

"When I started as a principal, it was not easy because the formal principal was a male and I am a female, mostly about the learner. When I tell them how to behave in school and give instructions, they take it for granted because I am a female, and they believe I am just making it up, and it's not a constitutional requirement or stipulated code of conduct. I experienced indiscipline from learners like late coming and other disturbing acts". (P4 /SCH 4)

SCH 9/P9 also mentioned that:

"The relationship at first was very bad because I am the first female principal in this school, you can imagine, people were saying she can't cope, and she will bring the result down and all. Students were not used to having a female principal at all, so they had a negative attitude towards me". (SCH 9/P9)

The above quotations highlight that the female principals are faced with a lack of cooperation and being undermined by the learners due to their gender. Learners undermine the authority of the female principals, making it difficult for them to effectively manage the learners, as evidenced by the rebellious acts of the learners, which caused great worry for the principals. Traditionally, positions of power were primarily dominated by males, and it became a socially acceptable norm for males to take up the most superior positions. Due to this, women who defy social expectations by taking up leadership positions face various challenges and lack cooperation. The results support work by Faulkner (2015), who found that female principals' experiences are adversely influenced by the prevailing and entrenched patriarchal attitudes within the communities that they serve, which learners adopt.

In explaining the negative attitude experienced by the learners, one of the principals linked this behaviour to the lack of motivation on the part of the learners due to the community's economic status, which is characterised by the absence of opportunities. $\mathrm{SCH} 4 / \mathrm{P} 4$ specified that: 
"And the learners, they are not motivated because of their background, and it is a deep rural area ... in short poverty influences them to behave negatively, and they live without ambition". ( $\mathrm{SCH} 4 / \mathrm{P} 4)$

The above indicated the status of the community, which results in the learners having no prospects for growth or achievement, leading to diminished aspirations for a better life. Learners did not perceive the benefit of going to school, which led to a lack of seriousness with their school work. Consequently, they had no adherence to the stipulated rules, making it difficult for the principals to enforce them, resulting in a negative relationship with the learners. The situation supports the view of Naidoo and Perumal (2014) that environmental conditions harm the curriculum because they do not contribute to academic stimulation, and do not support the aspirations of learners.

In contrast to the above, the other principals highlighted positive experiences with their learners which was shown by their learners' the cooperation, good behaviour, and seriousness. This experience was fulfilling to the female principals as this helped them take up their role in guiding and supporting the learning process of these learners. It is pointed out by $\mathrm{SCH} 1 / \mathrm{P} 1$, who emphasised the respect she gets from her learners as follows:

"With me here, the relationship is good with learners; they respect me, they listen to me whenever I reprimand them, especially when they do something wrong, they listen to me and change their behaviour. So I feel the relationship is good even though you have to work harder than your male counterpart to make this happen". (SCH 1/P1)

The quotation indicates a good and reciprocal relationship between the learners characterised by cooperation and respect, which gave the principal motivation and the energy to support the learners to become better people. Although good rapport has been noted, the quote indicates that female principals have to make a special effort in building relationships with their learners, which is not the case with their male counterparts. It clearly shows that some gender influence is barricading the process that female principals have to break for them to succeed in their work. The work of Silva and Mendis (2017) corroborates this finding. Accordingly, the efforts of these principals indicate that the transformational leadership style they align themselves with is congenial to women. Some of their components are relatively communal. Nevertheless, these particular communal behaviours help female leaders deal with the unique problems of lesser authority (in this case students).

\section{Relationship Experiences with the Teachers}

In light of the relationship with the teachers, a more significant proportion of the participants have ill-relationship with teachers, mostly at first, while very few enjoyed good relationships. For example, 
$\mathrm{SCH} 4 / \mathrm{P} 4$ voiced her experience with the teachers as unpalatable in the following manner:

"When it comes to the educators, they just undermine the female principal in things which must be done. For example, in our school, there is a 3 in 1 sporting facility and when it was under construction, there was a tug of war between the educators and the SGB because all the property in school is controlled and overseen by the SGB. To achieve that construction, it was a war. The educators just don't want to understand your explanation or support you because to them they think you are just making up all the procedures. Meanwhile, it was the right procedure to follow by involving the $S G B$ in all this, and that is a problem with the educators". (SCH 4/P4)

The explanation by the participant indicates the lack of cooperation from the teachers who are stakeholders in the success of the school's goal. In addition, it might be attributed to the principal being female, which makes the educators have less confidence in her leadership and reluctant in supporting her vision. SCH 7/P7 highlighted this by shedding more light on the aspect of societal norm and female leadership unacceptance as follows:

"The relationship with teachers as a female principal is not that good in the sense that as we know in our society, we have this problem of patriarchy, in the sense that men are seen to be the people who are supposed to be rulers and even in schools they still believe that the principal is supposed to be a man. Because of this, I am been undermined as a principal, and because of this, the relationship is not that good". (SCH 7/P7)

It clearly shows the role of patriarchy in making women less acceptable as leaders in society and makes it difficult for them to question certain cultures and practices as the work of Potokri (2015), the 'exposition of culture' illuminates. Both men and female teachers in this society come from a culture characterised by male dominance. A women's place is considered home, and males are seen as breadwinners (Potokri, $2011,2015)$. When women make it into the top positions, they are mostly met with resistance. This finding is supported by Booysen and Nkomo (2010). They argue that female principals find male counterparts or teachers uncooperative due to societal authority and views they want to maintain even in the workplace. Women are still regarded as homemakers, whereas most males are employed outside the home (Posel \& Bruce-Brand, 2020). Such stereotyping makes it difficult for women to conduct their duties and retain their leadership positions.

In addition, the article revealed that principals who lead the same schools where they were teachers before they were appointed principals reportedly have difficulty gaining the respect of teachers. 
For example, one of the principals ( $\mathrm{SCH} 6 /$ P6) described her own experience with the teachers as sour because she worked with them before being promoted.

"Because I was working together with them as an educator, and they seem not to understand that it is real that I am now a principal. Some couldn't take my instructions easily because they still think I am an educator like them and not a leader. The bottom line is the relationship was not that good". ( $\mathrm{SCH} 6 / \mathrm{P} 6)$

The above indicates the lack of cooperation from colleagues. Thus they cannot acknowledge and accept the superiority of the principal to the extent of not listening to her directive. Various studies reveal the lack of cooperation of teachers due to the perception that female principals are incapable of leading educational institutions (for example, see Parsaloi, 2012; Schmidt \& Mestry, 2015). Booysen and Nkomo (2010) assert that female principals find male counterparts or male teachers uncooperative because they are used to society's respect, thus making it difficult to work under women's leadership. In some cases as Syed's (2018) work revealed, some male teachers quit their jobs to avoid being under a woman's leadership. Jean-Marie and Martinez (2013) and Schmidt and Mestry (2015) also highlighted that those female colleagues expected to be more supportive to the female principals also show a lack of support. Again, it might be attributed to how they were brought up and making them reluctant to accept female principals as their leaders.

Another participant indicated that tribalism also contributed to the negative experience of principals. SCH 10/P10 explained:

"Because I was brought into this village to head the school from another location, the thing called "son of the soil" affect the way they treat me because they feel that the position should have been given to one of them and not me... this was more with the teachers. ... a few teachers, they feel like the position should have been given to a man and not a woman". (SCH 10/P10)

It explains the role of tribalism in the reluctance of some teachers to accept the principals from other cultures or places outside their community. Principals from within the community are more likely to receive support in doing their work than outside communities. It shows the intersectional challenges that some female principals encountered. They are discriminated against not just because of their gender but also because of their different tribes.

Nonetheless, a few principals indicated that they enjoyed good relations with the teachers. These relationships were characterised by cooperation and respect. Participant SCH 1/P1 said:

"With my teachers, it's a good relationship because I haven't seen any educator with a bad or negative 
attitude because whatever I tell them to do, they do". (SCH 1/P1)

Similarly, SCH 10/P10 was also in line with others she said

"When it comes to the educators, we also have a wonderful relationship because we don't regard ourselves as Mr or Mrs. We regard ourselves as Brother and Sister like a family". (SCH 10/P10)

This good relationship appeared to be one of a kind as few principals indicated enjoying this unique kind of relationship with their teachers. Other participants indicated that they wished to have such a wonderful and cordial relationship with their subordinates.

The relationship experiences of most of the principals with their teachers suggest that there is an adverse reaction from the teachers no matter how hard the principals try to make the relationship work. Crucial to transformational leadership, Carli (2001) asserts that these adverse reactions can be minimised when female leaders are careful in displaying warmth and lack of self-interest, such as by expressing agreement, smiling, supporting others, and explicitly stating an interest in helping others reach their goals. However, these findings concerning the relationship of the principals with teachers herein seem to suggest otherwise. The participants demonstrated support for their teachers and showed interest in helping them reach their goals just like they did for their students. Nevertheless, most teachers did not change their innate or traditional beliefs of the female vs male leadership discourse because they did not see female leaders as mentors who can attend to their individualised considerations and needs.

\section{Relationship Experience with Parents}

One sub-theme that emerged from the data collected was the principals' relationship experience with the parents of their learners. Some of the participants indicated that their relationship with their parents was not pleasant. For example, SCH 1/P1 highlighted having a good relationship experience with both learners and teachers. However, interestingly she had a different experience when it came to her parents.

"With parents, when you call them to meetings they don't, most of them don't come, it's like they are not serious am not sure maybe it's because the principal is a woman or not. Thus, the relationship here is not good because there is a lack of commitment from the parents 'side, which in itself can be frustrating". (SCH 1/P1)

SCH 10/P10 also explained that:

"As for the parents, they feel like the position should have been given to a man and not a woman, for instance, one parent even recently went to the extent of saying that we thought that this woman won't make it here because we think females cannot become leaders". (SCH 10/P10) 
Statements by the participants indicate the lack of teamwork from the parents in moulding young people or the learners to be better people. Furthermore, the quotations show the lack of concern from the parents' side in taking part in decisions that affect their children's future. It is evident by their unresponsiveness when they are invited to meetings by the principal. Such a situation makes it difficult for the principals to effectively lead or manage the school towards outstanding achievements and the creation of future leaders. Additionally, some participants explained that parents do not take them seriously because they were born in the same village currently serving as principals. Thus, the order of the day is the societal stigma, gender discrimination, lack of commitment, negative attitudes and lack of belief that females can perform in the role of a principal. In agreement with this, Ndebele's (2018) asserted that women principals are painfully and powerfully exposed to gender discrimination because leadership is popularly attached to masculinity. Also, the studies of Parsaloi (2012) and Schmidt and Mestry (2015) revealed that women are often perceived as incapable of leading educational institutions due to the entrenched culture of male dominance. It is similar to the struggles faced by the Vhembe female principals. Their responses or views are reported in this article.

Despite the enormous sour relationship experienced by some participants with the parents, of SCH 10/P10's experience was eye-catching because her experience with learners, teachers, and parents seems to be consistently good and sound. She indicated that:

"The relationship with the parents is good because if not for the support from the parents I won't have the kind of learners that I have, and I won't have the great relationship that I have with the learners been that I am in a deep rural area. We have got this family kind of relationship, which I also emphasise with the learners and the educators. The good relationship with parents gives rise to peace and harmony in the school". (SCH 10/P10)

Maintaining a good relationship between the principal and the parents of the learners is essential in achieving learners' success and the success of the school's activities. As SCH 10/P10, her relationship experiences with the parents were very positive, and she equated their relationship to a family kind. It enabled the principal to lead the school without facing resistance from the parents correctly. This finding corroborates Ndebele's (2018) where parents were indicated to support the female principals due to of the trust relationship between the two parties. Yulianti et al. (2020) adds that teachers should be in a good relationship with the school leaders and parents because they are important agents within the school organisation to promote parental involvement. Unfortunately, this is not the case with the relationship between the sampled principals and most teachers. 
Based on this, the unhealthy relationship experienced by principals from some parents is thus not surprising because it concurs with Yulianti et al.'s assertion.

\section{Relational Experiences with the Community}

When sharing their experiences, some of the participants pointed out that they were happy with the support they receive from their community whilst other participants were not so impressed. Nevertheless, the vast majority of the participants asserted that the community was supportive to a large extent. For example, one of the participants ( $\mathrm{SCH} 8 / \mathrm{P} 8)$ said this in the following manner:

\section{"I am happy because the traditional} leaders in the community are supportive because we also support them during community rituals and other things." It can be deduced that there seems to be a two-way relationship between the community and the school without which the relationship can go entirely sour overnight”. (SCH 8/P8)

From the above, it can be deduced that there is a reciprocal relationship between the community members and the principal. It is because of the cooperative attitude and the principal's involvement in the events taking place in the community. Working with the community creates cordial relationships and support because they perceive the principal as their own and a stakeholder interested in the community's development.
Despite the amicable relationship with the community reported by some participants, some were not impressed. For example, participants $\mathrm{SCH} 3 / \mathrm{P} 3$ and $\mathrm{SCH}$ $8 / \mathrm{P} 8$ pointed out that the community is far from giving adequate support because they lack knowledge about the school and educational matters. They hardly care whether the school activities run smoothly or not. SCH 8/P8 said:

"Sometimes during class lessons,
or examination some members of
the community will be playing loud
music and having a bash, and when
you try to tell them that the learners
are learning or writing exams,
they just turn deaf ears to you like
you do not matter and continue
with their noise and disturbance
anyways." "This is so annoying and
disrespectful". (SCH 8/P8)

The statement by one of the principals indicates a lack of cooperation and concern by the community in supporting a conducive environment for the learners to study. Even though the principal tries to make them understand by talking to them, they show resistance and disregard her opinion. It might be due to the community not valuing education given the socio-economic status making them not see the benefits of education. Undermining of the principal's authority might also be attributed to their gender. This finding is in line with previous studies. In rural communities, community members still view the role of principalship as a male role. Therefore, the patriarchal 
culture limits the support of female principals by the community members, making it difficult for them to effectively manage the schools (Arar \& Abramovitz, 2013; Makgoka, 2016).

\section{Support from the Department of Education (DOE)}

One of the revelations or findings of this article indicates that some principals receive adequate support from the Department of Education through constant officials' visits to the school. The department checks on how the learners and teachers are faring, providing workshops and seminars, and connecting them with other relevant third parties such as social workers and the police when needed. It is aptly captured in some of the following quotations.

"The support from the department is high for us, our circuit manager is always here to monitor and give support in order to know of any of our challenges. The curriculum advisors are always here to give support to subject educators. Even the district director visits us like twice per term to show us support. If you check our final results, we produce better than our male counterparts in the area because we are always working hard as female principals due to the support which motivates us to work more". (SCH 1/P1)

Participants SCH 3/P3 also shared her experience as follows:
"The support that I am having now is from the circuit manager and she's very much supportive and visited us even at night to motivate us during our study camps around 7 pm and left around half9. Her presence really motivated us and inspired the learners and the teachers. It was the first time I saw a circuit manager show support to what we are doing". (SCH 3/P3)

Support from the DoE officials, as indicated above, encouraged the female principals to work extra hard, which made their students excel and their schools produce very good results.

In contrast, some participants explained that they do not have good relationship experience with the DoE. For example, $\mathrm{SCH}$ 10/P10 sadly explained her experience when it comes to receiving support from the DoE as follows:

"The support is not there yet, because, in our school that is led by me, we should be having people like counsellors to visit more often and check on the school progress and on us to see how we are doing, to guide us and orientate us, nobody is there to do that, at least quarterly they should visit. So the support is really weak. Though they organise workshops, but these workshops won't serve any meaningful purpose if they don't visit handson, especially for us ladies". (SCH 10/P10) 
From the statement by SCH $10 / \mathrm{P} 10$, it can be deduced that some of the female principals in rural areas do not receive the necessary support from the DoE. As a result, this makes it difficult for the principals to execute their duties and keep motivated because they feel left out and isolated. From the principals' perspective, visitations and frequent involvement of officials from the DoE are essential for executing the duties entrusted to them. This finding corroborates a study by Chisholm (2001). Chisholm's study posits that female principals lack desirable recognition, perceptibility, and sustenance from the side of DoE officials. It might be attributed to the fact that higher positions in the DoE are male-dominated, and to maintain this dominance, little support is given to principals who pose a threat to patriarchy (Naidoo \& Perumal, 2014).

\section{CONCLUSION}

This article aims to explores female school principals' experiences to understand how they manage their schools in the rural Vhembe District of South Africa. In managing their schools, principalsfemale leaders exhibit the qualities of transformational leadership style. They are comfortable with the leadership style because of their beliefs and gender roles/qualities. Being women, transformational leadership provides them with the leverage to use their natural female qualities such as personifies communicating, caring, supportive and considerate behaviours to support their subordinates and communities-students, teachers, and parents. Findings suggest that they are coping with the management of their schools amidst their frustrations mainly caused by the roles, capabilities, and interpretations that society ascribes to gender and leadership. The participants are not happy nor successful in overcoming their leadership obstacles or challenges. However, we argue that competence in their natural gender roles or qualities, which are the transformational leadership, kept them in their leadership role despite the challenges and frustrations they encounter and respond.

Although there has been significant progress in South Africa in the numbers of women taking up leadership positions in education, still a lot needs to be done to ensure gender equality in school leadership. Despite the hard work of female principals, the article indicates that the challenges they encounter impede them from successfully managing and implementing the change they desire in their schools. The principals rely on the cooperation of learners, parents, teachers, the community, and the DoE as important stakeholders in the success of the schools. So, cooperation between the leader (principals) and subordinates (for example, learners, teachers, and parents) is cardinal to successful leadership especially for women whose experiences are different from their male counterpart, as reviewed literature also reveals.

Participants' experiences in this article are unpleasant in many instances. Nonetheless, they demonstrate selflessness in their daily leadership tasks and routines. Furthermore, they are inspirational and serve 
as role models to all they had relationships with for the transformation and change they desire in their schools. To the participantssampled principals, being selfless and inspirational is their leadership strength and one way of the few mentioned to becoming a leader they aspire. Nonetheless, they would need government and institutional support in the form of policies targeted at the reorientation and thinking reconfiguration of their male counterparts and society about female leadership. Otherwise, successful leadership, particularly the transformational style, will remain a dream. The theory applies well when the underlining barriers affecting women to rise in leadership positions are addressed.

\section{ACKNOWLEDGEMENT}

The authors would sincerely like to thank all participants of this study for their roles and cooperation.

\section{REFERENCES}

Arar, K., \& Abramovitz, R. (2013). Teachers' attitudes toward the appointment of women as school leaders: The case of the Arab education system in Israel. Management in Education, 27(1), 3238. https://doi.org/10.1177/0892020612459188

Babbie, E., \& Mouton, J. (2010). The practice of social research (10th ed.). Oxford University Press Southern Africa.

Bass, B. M., \& Avolio, B. J. (1990). Transformational leadership development: Manual for the multifactor leadership questionnaire. CA Consulting Psychologist Press.

Batton, C., \& Wright, E. M. (2019). Patriarchy and the structure of employment in criminal justice: Differences in the experiences of men and women working in the legal profession, corrections, and law enforcement. Feminist Criminology, 14(3), 287-306.

Booysen, L. A., \& Nkomo, S. M. (2010). Gender role stereotypes and requisite management characteristics. Gender in Management: An International Journal, 25(4), 285-300.

Botes, W. (2014). Female teachers' experiences of senior male colleagues' exercising of power in schools [Master's dissertation]. North-West University.

Brothers, L. (2020, February 7). Women in parliament - How does SA rank? South Africa Good News. https://www.sagoodnews.co.za/heading-womenin-parliament-how-does-sa-rank/

Burns, J. (1978). Leadership. Harper \& Row.

Carli, L. L. (2001). Gender and social influence. Journal of Social Issues, 57(4), 725-741.

Chabalala, W. L. (2006). What do women teachers identify as barriers to promotion? [Doctoral dissertation]. University of Pretoria.

Chisholm, L. (2001). Gender and leadership in South African educational administration. Gender and Education, 13(4), 387-399.

Creswell, J. W. (2014). A concise introduction to mixed methods research. SAGE Publications.

Cubillo, L., \& Brown, M. (2003). Women into educational leadership and management: International differences? Journal of educational Administration, 41(3), 278-291. https://doi. org/10.1108/09578230310474421

Davids, N. (2018, August 1). Female principals in South Africa: The dynamics that get in the way of success. The Conversation. https:// theconversation.com/female-principals-in-southafrica-the-dynamics-that-get-in-the-way-ofsuccess-100698

Denmark, V. (2012). Transformational leadership - A matter of perspective. SCRIBD. https:// 
www.scribd.com/document/279170597/ Transformational-Leadership

Department of Education. (1996). South African Schools Act of 1996. DoE Policy Document.

Department of Education. (2008). Understand school leadership \& governance in the South African context. https://www.education.gov. za/Portals/0/Understand_school_leadership_ and_governance_in_the_South_Afr. pdf?ver=2009-10-14-125049-867

Diko, N. (2014). Women in educational leadership: The case of hope high school in the Eastern Cape Province, South Africa. Educational Management Administration \& Leadership, 42(6), 825-834.

English, F. W. (2008). The New McCarthyism: The right wing's assault on American academic thought. In E. A. Samier \& A. G. Stanley (Eds), Political approaches to educational administration and leadership (pp. 252-268). Routledge.

Faulkner, C., (2015). Women's experiences of principalship in two South African high schools in multiply deprived rural areas: A life history approach. Educational Management Administration \& Leadership, 43(3), 418-432.

Flanders, M. L. (1994) Breakthrough: The career woman's guide to shattering the glass ceiling. Paul Chapman Publishing.

Gibbons, J. L., Poelker, K. E., \& Moletsane-Kekae, M. (2017). Women in South Africa: Striving for full equality post-apartheid. In Women's evolving lives (pp. 141-159). Springer.

Gibbs, G. R. (2007). Analysing qualitative data. Sage Publications.

Jean-Marie, G., \& Martinez, A. (2013). Race, gender, \& leadership: Perspectives of female secondary leaders. In M. Nielsen \& M. S. Plakhotnik (Eds.), Proceedings of the Six Annual College of Education Research Conference: Urban and international education section (pp.
43-48). CORE. https://core.ac.uk/download/ pdf/46946571.pdf

Johnson, Z., \& Mathur-Helm, B. (2011). Experiences with queen bees: A South African study exploring the reluctance of women executives to promote other women in the workplace. South African Journal of Business Management, 42(4), 47-55.

Leithwood, K., Begley, P. T. \& Cousins, J. B. (1994). Performance appraisal and selection of school leaders: Selection processes and measurement issues. In Developing expert leadership for future schools (pp. 228-252). Falmer Press.

Makgoka, K. P. (2016). The leadership experiences of female secondary school principals in Sekhukhune District, Limpopo [Doctoral dissertation]. University of South Africa.

Marks, H. M., \& Printy, S. M. (2003). Principal leadership and school performance: An integration of transformational and instructional leadership. Educational Administration Quarterly, 39(3), 370-397.

Mestry, R., \& Du Plessis, P. (2020). South Africa: Education authorities and public schools: The organisation and impact of policies in South Africa. In Educational Authorities and the Schools (pp. 371-388). Springer.

Mestry, R., \& Schmidt, M. (2012). A feminist postcolonial examination of female principals' experiences in South African secondary schools. Gender and Education, 24(5), 535-551.

Moorosi, P. (2008). Creating linkages between private and public: Challenges facing women principals in South Africa. South African Journal of Education, 27(3), 507-521.

Moraka, N. V. (2018). An African feminist study of talent management practices applied to improve gender equality in JSE-listed South African mining boards: A multiple case analysis [Doctoral dissertation]. University of South Africa. 
Naidoo, B., \& Perumal, J. (2014). Female principals leading at disadvantaged schools in Johannesburg, South Africa. Educational Management Administration \& Leadership, 42(6), 808-824.

Ndebele, C. (2018). Gender and school leadership: Breaking the glass ceiling in South Africa. Multidisciplinary Journal of Gender Studies, 7(2), 1582-1605.

Parsaloi, M. (2012). Lived experiences of female head teachers in rural primary schools in Kenya [Unpublished Master's thesis]. University of South Africa.

Posel, D., \& Bruce-Brand, J. (2020). 'Only a housewife?' Subjective well-being and homemaking in South Africa. Journal of Happiness Studies, 22(1), 1-20.

Potokri, O. C. (2011). The academic performance of married women students in Nigerian higher education [Doctoral dissertation]. University of Pretoria.

Potokri O. C. (2015). Exposition of culture and the space of women: An African view for policy consideration. Gender and Behaviour, 13(2), 6694-6703.

Rigg, C., \& Sparrow, J. (1994). Gender, diversity and working styles. Women in Management Review, 9(1), 9-16.

Schmidt, M., \& Mestry, R. (2015). The experiences of female principals in the Gauteng province. American Journal of Educational Research, 3(7), 813-821.

Silva, D. A. C. S., \& Mendis, B. A. K. M. (2017). Male vs female leaders: Analysis of transformational, transactional \& laissez-faire women leadership styles. European Journal of Business and Management, 9(9), 19-26.

Silverman, D. (2010). Doing qualitative research. Sage Publications.

Syed, N. (2018, December 17). Are teachers more likely to quit under female leaders? The Educator Australia. https://www.theeducatoronline.com/ k12/news/are-teachers-more-likely-to-quitunder-female-leaders/258686

Younger, M., \& Cobbett, M. (2014). Gendered perceptions of schooling: Classroom dynamics and inequalities within four Caribbean secondary schools. Educational Review, 66(1), 1-21.

Yukl, G. (1989). Managerial leadership: A review of theory and research. Journal of Management, 15(2), 251-289.

Yukl, G. (2005). Leadership in organizations (6th ed.). Prentice-Hall.

Yulianti, K., Denessen, E., Droop, M., \& Veerman, G. J. (2020). School efforts to promote parental involvement: The contributions of school leaders and teachers. Educational Studies, Ahead-ofPrint, 1-16. https://doi.org/10.1080/03055698. 2020.1740978

Zikhali, J. T., \& Smit, B. (2019). Women leaving leadership: Learnings from female school principals in Gauteng Province, South Africa. Pertanika Journal of Social Sciences \& Humanities, 27(1), 475-489.

Zuma, N. (2018). Experiences and practices of black women teachers: A case study of a rural secondary school in KwaZulu-Natal, South Africa [Master's dissertation]. Durban University of Technology. 